\title{
ROLO DESTORROADOR APÓS A SEMEADURA DO TRIGO ${ }^{1}$
}

\section{LUIZ C. GARCIA ${ }^{2}$, CARLOS B. MORGADO ${ }^{3}$, ROGÉRIO DYCK ${ }^{3}$, ROBERTO JASPER ${ }^{4}$, ALLISON J. FORNARI ${ }^{5}$}

\begin{abstract}
RESUMO: Teve-se o objetivo de verificar a influência do rolo destorroador utilizado após a semeadura do trigo, sobre palhada de milho, em duas unidades de produção agrícola. As variáveis analisadas foram: população de plantas 15 dias após a emergência, população de plantas com espigas, grãos por espiga, massa de 1.000 grãos, produtividade e viabilidade econômica da operação. A significativa elevação da população de plantas emergidas com o emprego do rolo destorroador não refletiu nos componentes de produção. Portanto, não se recomenda sua utilização nas condições experimentais.
\end{abstract}

PALAVRAS-CHAVE: plantio direto, componentes de produção, palhada de milho.

\section{ROLLER AFTER WHEAT SOWING}

\begin{abstract}
This experiment was carried out to verify the influence of a roller after wheat sowing under corn stover, in two farming areas. The variables studied were: plant population 15 days after seedling, population with cobs, grains per cob, 1000 seed weight, yield and the economic viability of the operation. The significant increase of emerged plants after the usage of a roller didn't reflect in the yield components. Therefore it's not recommended in experimental conditions.
\end{abstract}

KEYWORDS: no-tillage, yield components, corn crop residue.

\section{INTRODUÇÃO}

O rolo destorroador consiste em uma máquina que destrói torrões do solo produzidos em operações agrícolas anteriores. Também pode ser utilizado para melhorar a estrutura física do solo, devido à eliminação de bolsões de ar e de torrões endurecidos, o que possibilita melhor contato da semente com o solo, afetando positivamente a germinação. O rolo destorroador também pode ser usado para a compactação de leitos de estradas ou carreadores (GADANHA JÚNIOR et al., 1991).

WILIKINSON \& BRAUNBERCK (1977) recomendam usar cobridores compactadores, cuja função é cobrir as sementes com solo úmido, pressionar o solo para facilitar o movimento de água por capilaridade e, ao mesmo tempo, conservar o solo suficientemente solto para minimizar o encrostamento superficial e não dificultar a emergência das plântulas. GADANHA JÚNIOR et al. (1991) afirmam que, para haver melhor homogeneidade da palhada, pode-se utilizar rolo destorroador ou grade niveladora destravada, após a semeadura.

No caso de precipitação, logo após a semeadura, a utilização do rolo destorroador deve ser eliminada, pois a chuva contribui no cobrimento e na germinação das sementes (PEDROTTI \& DIAS JÚNIOR, 1996).

Os fatores que determinam o comportamento do solo são: granulometria, teor de matéria orgânica, umidade do solo (BODMAN \& CONSTANTIN, 1965), além do estado de compactação (SILVA et al., 2000). A compactação do solo provoca modificações na estrutura, caracterizadas pela redução da macroporosidade e pelo aumento da microporosidade (IMHOFF et al., 2000; HOAD et al., 2001). O tráfego sistemático de máquinas pode promover compactação excessiva na

\footnotetext{
${ }^{1}$ Financiado pela PLÂNTULA Comércio Agropecuário Ltda.

${ }^{2}$ Eng $^{\text {o }}$ Agrônomo, Doutor, PLÂNTULA, Ponta Grossa - PR, Fone: (0XX42) 3229.5010, luizclaudiogarcia2001@yahoo.com.br.

${ }^{3}$ Acadêmico de Agronomia, Universidade Estadual de Ponta Grossa - UEPG, Ponta Grossa - PR.

${ }^{4}$ Eng ${ }^{0}$ Agrônomo, Professor, Universidade Estadual de Ponta Grossa - UEPG, Ponta Grossa - PR.

${ }^{5}$ Engo Agrônomo, Fazenda Paiquerê, Piraí do Sul - PR.

Recebido pelo Conselho Editorial em: 20-11-2007
}

Aprovado pelo Conselho Editorial em: 26-5-2008 
superfície do solo, principalmente em solos com elevados teores de argila (SALIRE et al., 1994; TORMENA \& ROLOFF, 1996, HAKANSSON \& VOORHEES, 1996). Estudos como os de ROSOLEM et al. (1999) demonstram que a compactação ocorre com mais freqüência e intensidade em Latossolos.

Analisando a compactação do solo em área de plantio direto, SECCO et al. (2004) encontraram reduções significativas nas populações de plantas com cinco passagens de rolo compactador em comparação com a testemunha. MEDEIROS et al. (2005) concluíram que as plantas de arroz em vasos tiveram decréscimo de $24 \%$ no número de perfilhos, com máxima compactação, comparado ao nível mínimo. RIBEIRO (1999) também observou redução linear no número de perfilhos de arroz com o aumento da compactação. No manejo da palhada, embora o uso do rolo compactador seja amplamente disseminado, resultados indicaram que o mesmo não apresentou benefícios significativos ao crescimento e à produtividade da soca de arroz irrigado (SANTOS \& PRABHU, 2003).

Segundo a Fundação ABC (2006), o custo da operação com rolo destorroador, na região dos Campos Gerais, foi de $\mathrm{R} \$ 12,40$ por hectare. O preço de venda do trigo, na mesma região e época, foi de $\mathrm{R} \$ 18,00$ a saca de $60 \mathrm{~kg}$ (AGROLINK, 2006).

O objetivo deste trabalho foi avaliar a ação do rolo destorroador na semeadura do trigo sobre palhada de milho em duas unidades de produção agrícola com solos distintos.

\section{MATERIAL E MÉTODOS}

O experimento foi realizado em duas unidades de produção agrícola na região dos Campos Gerais, no Estado do Paraná, localizada nas coordenadas $25^{\circ} 16^{\prime}$ de latitude sul e $50^{\circ} 16^{\prime}$ de longitude oeste, clima $\mathrm{Cfb}$, em sistema plantio direto sob a palha, com diferentes situações, nas duas propriedades analisadas.

A Fazenda Mutuca está localizada no município de Arapoti - PR, a 960 m de altitude, solo classificado como Latossolo Vermelho eutróficos, com análises química e física descritas nas Tabelas 1 e 2 . Na área onde o experimento foi instalado, havia 5,9 $\mathrm{t} \mathrm{ha}^{-1}$ da palhada de milho, colhido em 9 de abril de 2005. A variedade de trigo ONIX $^{\circledR}$ foi semeada em 2 de junho de 2005, com população de 3.300 .000 sementes por ha, pela semeadora-adubadora $\mathrm{SSM}^{\circledR} 27$, tracionada pelo trator $\mathrm{CBT}^{\circledR} 8060$ - $75 \mathrm{~kW}(100 \mathrm{cv})$. A semeadora-adubadora estava montada com 27 unidades de semeadura do tipo rotor canelado, abertura de sulco com disco duplo desencontrado para colocação de sementes e adubo, com rodas limitadoras de profundidade e sem sistema de fechamento de sulco (retirado).

TABELA 1. Análise química do solo, de 0 a $20 \mathrm{~cm}$, das Fazendas Mutuca e Paiquerê, região dos Campos Gerais - PR, em maio de 2005. Chemical analysis of soil, from 0 to $20 \mathrm{~cm}$, of the Mutuca and Paiquerê Farms, in the region of Campos Gerais - PR, Brazil, on May 2005.

\begin{tabular}{|c|c|c|c|c|c|c|c|c|c|c|c|}
\hline \multirow{2}{*}{ Fazendas } & \multirow{2}{*}{$\mathrm{pH}$} & $\mathrm{H}+\mathrm{Al}$ & $\mathrm{Al}$ & $\mathrm{Ca}$ & $\mathrm{Mg}$ & $\mathrm{K}$ & \multirow[t]{2}{*}{ CTC } & \multirow{2}{*}{$\frac{\mathrm{P} \text { (Mehlich) }}{\mathrm{mg} \mathrm{dm}^{-3}}$} & \multirow{2}{*}{$\frac{\mathrm{MO}}{\mathrm{g} \mathrm{dm}^{-3}}$} & \multirow{2}{*}{$\frac{\mathrm{V}}{\%}$} & \multirow{2}{*}{$\begin{array}{c}\mathrm{Al} \\
\% \\
\end{array}$} \\
\hline & & & & $\mathrm{mms}$ & $\mathrm{dm}$ & & & & & & \\
\hline & 62 & 44 & 3,0 & 28 & 15 & 4,1 & 92 & 15,4 & 2,2 & 52 & 0,6 \\
\hline Paiquerê & 5,0 & 75 & 8,0 & 70 & 26 & 3,9 & 174 & 6,4 & 4,7 & 57 & 0,8 \\
\hline
\end{tabular}

Na Fazenda Paiquerê, a 950 m de altitude, situada no município de Piraí do Sul - PR, o solo foi classificado como Latossolos Vermelhos distróficos, com análises química e física apresentadas nas Tabelas 1 e 2. A palhada de milho do híbrido P30F44, no local destinado à cultura do trigo, estava em torno de $6,3 \mathrm{t} \mathrm{ha}^{-1}$, colhida em $1^{\circ}$ de abril de 2005 . A semeadura da variedade ONIX ${ }^{\circledR}$, com população de 3.300.000 sementes por ha, ocorreu em 6 de junho de 2005. Utilizou-se do trator John Deere $^{\circledR} 7500$ - $106 \mathrm{~kW}(140 \mathrm{cv})$ e a semeadora-adubadora SSM $^{\circledR} 27$ com a mesma configuração da semeadora-adubadora da Fazenda Mutuca. 
TABELA 2. Análise física do solo, de 0 a $20 \mathrm{~cm}$, das Fazendas Mutuca e Paiquerê, região dos Campos Gerais - PR, em maio de 2005. Physical analysis of soil, from 0 to $20 \mathrm{~cm}$, of the Mutuca and Paiquerê Farms, in the region of Campos Gerais - PR, Brazil, on May 2005.

\begin{tabular}{cccc}
\hline Fazendas & Argila $\left(\mathrm{g} \mathrm{kg}^{-1}\right.$ de solo $)$ & Silte $\left(\mathrm{g} \mathrm{kg}^{-1}\right.$ de solo $)$ & Areia $\left(\mathrm{g} \mathrm{kg}^{-1}\right.$ de solo $)$ \\
\hline Mutuca & 260 & 150 & 590 \\
Paiquerê & 620 & 199 & 181 \\
\hline
\end{tabular}

O controle de plantas daninhas, pragas, doenças e adubação seguiu os padrões das fazendas, que têm como base as recomendações das COMISSÕES CENTRO-SUL BRASILEIRA DE PESQUISA DE TRIGO E TRITICALE (2004).

As colheitas foram realizadas em 26 de outubro e 6 de novembro de 2005, nas Fazendas Mutuca e Paiquerê, respectivamente.

As semeadoras foram reguladas para que a distribuição das sementes e dos fertilizantes ficasse a 0,03 m de profundidade. As sementes utilizadas tinham, no mínimo, 90\% de germinação e 98\% de pureza. Os depósitos de adubo e de sementes foram abastecidos a 50\% de sua capacidade. O teor médio de água no solo, na camada de 0 a $0,1 \mathrm{~m}$, foi de $28 \%$ em ambas as fazendas. A primeira precipitação, após o plantio, ocorreu em 17 de junho, com incidência de $18 \mathrm{~mm}$ na Fazenda Mutuca e $8 \mathrm{~mm}$ na Fazenda Paiquerê. Não houve deficiência hídrica durante o ciclo da cultura.

As pulverizações foram realizadas utilizando-se de pulverizador Columbia Tandem ${ }^{\circledR} 2.000 \mathrm{~L}$, tracionado por trator Valmet ${ }^{\circledR}$ 685, e um autopropelido Uniport $2.000 \mathrm{~L}$, nas Fazendas Mutuca e Paiquerê, respectivamente. $\mathrm{Na}$ adubação de cobertura a lanço, utilizou-se do equipamento Incomagdi ${ }^{\circledR}$ centrífugo, acoplado ao trator Massey Ferguson ${ }^{\circledR}$ 290, na Fazenda Mutuca, e um Amazone $^{\circledR} 1.500$, acoplado ao trator John Deere ${ }^{\circledR} 7.500$, na Fazenda Paiquerê.

Em cada fazenda, o delineamento experimental foi em blocos casualizados, com dois tratamentos, com ou sem a utilização do rolo destorroador, em 11 repetições por tratamento. As parcelas tinham $20 \times 40 \mathrm{~m}$. O tamanho da amostra levou em consideração a estabilização da média e do desvio-padrão das variáveis analisadas, conforme método proposto por KRANZ (1988).

O rolo destorroador de arrasto utilizado foi da $\mathrm{WAIGA}^{\circledR}$, tracionado por trator $\mathrm{CBT}^{\circledR} 8.440 \mathrm{e}$ John Deere ${ }^{\circledR}$ 6.405, respectivamente, nas Fazendas Mutuca e Paiquerê. A operação foi realizada logo após a semeadura. O implemento possuía três seções; cada seção tinha 3,80 m de largura e $900 \mathrm{~kg}$, totalizando $11,4 \mathrm{~m}$ e $2.700 \mathrm{~kg}$. A seção estava constituída de um chassi retangular ao qual era fixado um eixo sustentado por mancais. Cada eixo possuía 51 discos, sendo esses dispostos em seqüência alternada de lisos e dentados (Figura 1).

As variáveis medidas foram: população inicial (15 dias após a emergência - DAE), população com espigas, número de grãos por espiga, massa de 1.000 grãos, produtividade e viabilidade econômica da operação.

A colheita, a debulha, a contagem de grãos por espiga e a massa de 1.000 grãos foram realizadas manualmente. A massa de 1.000 grãos foi definida por meio de balança de precisão. A umidade foi constatada com o uso de medidor de umidade (G800 Gehaka $\left.{ }^{\circledR}\right)$. A massa de 1.000 grãos e a produtividade tiveram seus valores corrigidos para $13 \%$ de umidade. A viabilidade econômica foi definida pela comparação do custo da operação pelo acréscimo na produção.

Aplicou-se o teste de Hartley para a verificação da homocedasticidade das variâncias. As variáveis mensuradas foram submetidas ao teste F por haver apenas dois tratamentos. 


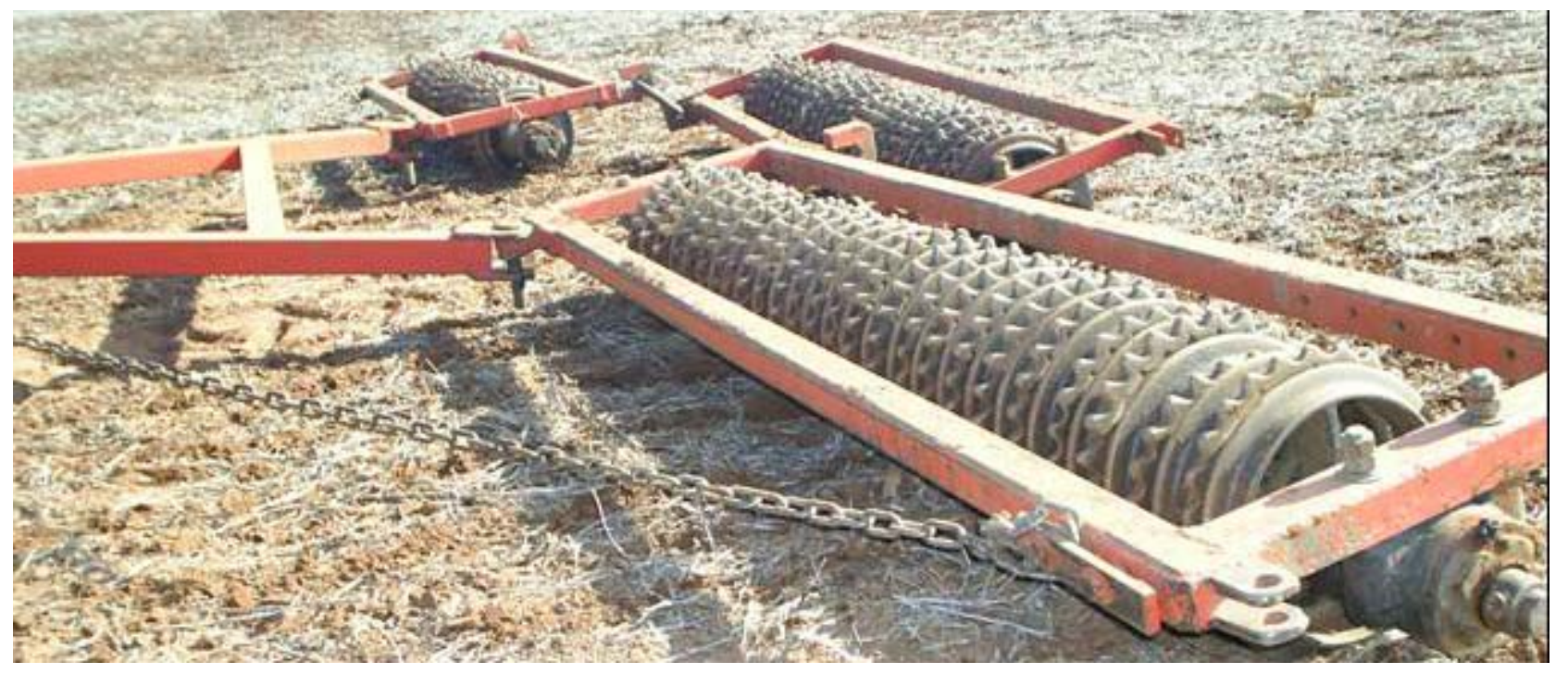

FIGURA 1. Rolo destorroador utilizado após a semeadura de trigo em sistema de plantio direto, na região dos Campos Gerais - PR. Roller used after sowing wheat in tillage system in the region of Campos Gerais - PR, Brazil.

\section{RESULTADOS E DISCUSSÃO}

Após a semeadura, a primeira precipitação ocorreu com 15 e 11 dias, nas Fazendas Mutuca e Paiquerê, respectivamente. Portanto, descartou-se a interferência desse fator nos resultados do experimento, como alerta PEDROTTI \& DIAS JÚNIOR (1996).

A estabilização da média e do desvio-padrão de todas as variáveis analisadas (KRANZ, 1988) ficou em $10 \mathrm{~m}^{2}$ por parcela. O teste de Hartley apontou a homocedasticidade das variâncias para todas as variáveis estudadas. Portanto, não houve necessidade de transformação das médias para aplicação do teste F.

A utilização do rolo destorroador elevou a população de plantas emergidas em 4,9 e 21,3\%, respectivamente, nas Fazendas Mutuca e Paiquerê, comparadas com a testemunha (Tabela 3). Como afirmaram WILIKINSON \& BRAUNBERCK (1977) e GADANHA JÚNIOR et al. (1991), é provável que a ação do rolo destorroador tenha melhorado a estruturação física do solo, devido à eliminação de bolsões de ar e de torrões endurecidos, possibilitando maior contato da semente com o solo, resultando em melhor germinação.

A diferença entre a testemunha e o emprego do rolo destorroador na Fazenda Mutuca, em relação à Fazenda Paiquerê, deve estar relacionada às características específicas de solo. A Fazenda Mutuca possui solo de textura arenosa, sendo a compactação mais difícil que em solos de textura argilosa como o presente na Fazenda Paiquerê, conforme IMHOFF et al. (2000) e HOAD et al. (2001).

TABELA 3. População de plantas de trigo 15 dias após a emergência (DAE), sem e com a passagem de rolo destorroador após a semeadura, em sistema de plantio direto na palha de milho, na região dos Campos Gerais - PR. Population of wheat plants 15 days after appearance (DAE) with and without the passage of the roller after planting, in tillage system in the corn straw in the region of Campos Gerais - PR, Brazil.

\begin{tabular}{ccc}
\hline \multirow{2}{*}{ Tratamentos } & \multicolumn{2}{c}{ População 15 DAE (plantas por ha) } \\
\cline { 2 - 3 } & Fazenda Mutuca & Fazenda Paiquerê \\
\hline Sem rolo destorroador & $2.699 .300 \mathrm{~B}^{1}$ & $1.967 .800 \mathrm{~B}$ \\
Com rolo destorroador & $2.837 .800 \mathrm{~A}$ & $2.500 .400 \mathrm{~A}$ \\
\hline C.V. $(\%)$ & 7,85 & 5,99 \\
\hline
\end{tabular}

${ }^{1}$ Médias seguidas de mesma letra na coluna não diferem entre si, pelo teste $\mathrm{F}(\mathrm{P}>0,05)$. 
As vantagens da utilização do rolo destorroador detectadas na população inicial não se mantiveram em relação aos componentes da produção (Tabela 4), que não diferiram estatisticamente entre si em todas as variáveis analisadas. Presume-se que a elevação do contato entre o solo e a semente, que favoreceu a germinação, pode ter inibido o perfilhamento das plantas de trigo a ponto de anular o benefício inicial. Portanto, confirmam-se as afirmações de RIBEIRO (1999), SECCO et al. (2004) e MEDEIROS et al. (2005). SANTOS \& PRABHU (2003) também não identificaram diferenças significativas nos componentes de produção na cultura do arroz com a utilização do rolo destorroador.

TABELA 4. Componentes de produção da cultura do trigo, sem e com a passagem de rolo destorroador após a semeadura, em sistema de plantio direto na palha de milho, na região dos Campos Gerais - PR. Components of production of the wheat crop, with and without the passage of the roller after planting, in tillage system in the corn straw in the region of Campos Gerais - PR, Brazil.

\begin{tabular}{ccccc}
\hline Tratamento & $\begin{array}{c}\text { Espigas } \\
(\mathrm{ha})\end{array}$ & Grãos por Espiga & $\begin{array}{c}\text { Massa de 1.000 } \\
\text { Grãos }(\mathrm{g})\end{array}$ & $\begin{array}{c}\text { Produtividade } \\
\left(\mathrm{kg} \mathrm{ha}^{-1}\right)\end{array}$ \\
\hline \multicolumn{5}{c}{ Fazenda Mutuca } \\
\hline Sem rolo destorroador & $5.025 .454^{1}$ & 33,58 & 25,48 & 4.237 \\
\hline Com rolo destorroador & 4.843 .636 & 31,75 & 27,93 & 4.229 \\
\hline C.V. $(\%)$ & 13,51 & 7,40 & 9,99 \\
\hline \multicolumn{5}{c}{ Fazenda Paiquerê } \\
\hline Sem rolo destorroador & 5.594 .117 & 34,42 & 24,04 & 4.608 \\
\hline Com rolo destorroador & 5.058 .823 & 34,20 & 23,88 & 4.069 \\
\hline C.V. $(\%)$ & 18,33 & 2,88 & 5,12 & 17,44 \\
\hline
\end{tabular}

${ }^{1}$ Teste $\mathrm{F}$ não-significativo para todas as variáveis analisadas $(\mathrm{P}>0,05)$.

Como o rolo destorroador foi tracionado por um trator, é importante ressaltar a compactação provocada pelo tráfego sistemático de máquinas, o que também pode ter contribuído para o resultado, conforme alertam SALIRE et al. (1994), TORMENA \& ROLOFF (1996) e HAKANSSON \& VOORHEES (1996).

Comparando-se os resultados entre Fazendas, a Paiquerê apresentou decréscimo nos componentes de produção em maior escala que a Mutuca. Pode-se atribuir essa tendência à diferença do teor de argila entre as propriedades (Tabela 2), como alertam TORMENTA \& ROLOFF (1996) e ROSOLEM et al. (1999).

Baseando-se nos dados da Fundação ABC (2006) e da AGROLINK (2006), pode-se quantificar economicamente o custo da operação (Tabela 5). Verificou-se elevação do custo da produção sem incremento na produtividade, tornando a operação inviável.

TABELA 5. Viabilidade econômica da utilização do rolo destorroador após a semeadura do trigo, em sistema de plantio direto na palha de milho, na região dos Campos Gerais - PR. Economic viability of using of roller after planting wheat, in tillage system in the corn straw in the region of Campos Gerais - PR, Brazil.

\begin{tabular}{cccc}
\hline Tratamentos & $\begin{array}{c}\text { Custo de Aplicação } \\
\left(\mathrm{R} \$ \mathrm{ha}^{-1}\right)\end{array}$ & $\begin{array}{c}\text { Acréscimo no Retorno } \\
\left(\mathrm{R} \$ \mathrm{ha}^{-1}\right)\end{array}$ & $\begin{array}{c}\text { Retorno Líquido } \\
\left(\mathrm{R} \$ \mathrm{ha}^{-1}\right)\end{array}$ \\
\hline \multicolumn{2}{c}{ Fazenda Mutuca } & \\
\hline Sem rolo destorroador & - & 2,43 & 2,43 \\
\hline Com rolo destorroador & 12,40 & 0 & $-12,40$ \\
\hline & \multicolumn{2}{c}{ Fazenda Paiquerê } \\
\hline Sem rolo destorroador & - & 161,51 & 161,51 \\
\hline Com rolo destorroador & 12,40 & 0 & $-12,40$ \\
\hline
\end{tabular}




\section{CONCLUSÕES}

A utilização do rolo destorroador aumentou o número de plantas de trigo emergidas. Os componentes de produção não foram influenciados pelo emprego do rolo destorroador. Como o rolo destorroador não incrementou a produtividade e elevou o custo da produção, desaconselha-se sua utilização em condições semelhantes que foram testadas no presente experimento.

\section{REFERÊNCIAS}

AGROLINK. Cotações do trigo. Disponível em:

$\mathrm{http}: / /$ www.agrolink.com.br/cotacoes/pg_cotacoes_uf.asp?p1=9839\&p2=27\&pg=2. Acesso em: 26 jan. 2006.

BODMAN, G.B.; CONSTANTIN, G.K. Influence of particle size distribution in soil compaction. Hilgardia, Berkeley, v.36, p.567-591, 1965.

COMISSÕES CENTRO-SUL BRASILEIRA DE PESQUISA DE TRIGO E TRITICALE. Informações técnicas das comissões centro-sul brasileira de pesquisa de trigo e de triticale. Londrina: IAPAR \& EMBRAPA, 2004. 218 p.

FUNDAÇÃO ABC. Custo de mecanização agrícola. Disponível em: http://www.fhonline.com.br/suporte/customecanizacao.xls. Acesso em:26 jan. 2006 .

GADANHA JÚNIOR, C.D.; MOLIN, J.P.; COELHO, J.L.D.; YAHN, C.H.; TOMIMORI, S.M.A. Máquinas e implementos agrícolas do Brasil. São Paulo: Instituto de Pesquisas Tecnológicas do Estado de São Paulo, 1991. 468 p.

HAKANSSON, I.; VOORHEES, W.B. Soil compaction. In: LAL, R.; BLUM, W.H.; VALENTIN, C.; STEWART, B.A. (Ed.). Methods for assesment of soil degradation. Boca Raton: Lewis Publishers, 1996. p.167-79.

HOAD, S.P.; RUSSEL, G.; LUCAS, M.E.; BINGHAM, I.J.. The management of wheat, barley, and oat root systems. Advances in Agronomy, New York, v.74, n.1, p.195-254, 2001.

IMHOFF, S.; SILVA, A.P.; TORMENA, C.A. Aplicações da curva de resistência no controle da qualidade física de um solo sob pastagem. Pesquisa Agropecuária Brasileira, Brasília, v.35, n.7, p.1.493-500, 2000.

KRANZ, J. Measuring plant disease. In KRANZ, J.; ROTEM, J. (Ed.). Experimental techniques in plant disease epidemiology. Heidelberg: Springer, 1988. p.35-50.

MEDEIROS, R.D.; SOARES, A.A.; GUIMARÃES, R.M. Compactação do solo e manejo de água I: efeitos sobre a absorção de N, P, K, massa seca de raízes e parte aérea de plantas de arroz. Ciência Agrotécnica, Lavras, v.29, n.5, p.940-7, 2005.

PEDROTTI, A.; DIAS JÚNIOR, M.S. Compactação do solo: como evitá-la. Agropecuária Catarinense, Florianópolis, v.9, n.4, p.50-2, 1996.

RIBEIRO, M.A.V. Resposta da soja e do eucalipto a fósforo em solos de diferentes texturas, níveis de densidade e de umidade. 1999. 71 F. Tese (Doutorado em Solos e Nutrição de Plantas) Universidade Federal de Lavras, Lavras, 1999.

ROSOLEM, C.A.; FERNANDEZ, E.M.; ANDREOTTI, M.; CRUSCIOL, C.A.C. Crescimento radicular de plântulas de milho afetado pela resistência do solo à penetração. Pesquisa Agropecuária Brasileira, Brasília, v.34, n.5, p.821-8, 1999.

SALIRE, E.V.; HAMMEL, J.E.; HARDCASTLE, J.H. Compression of intact subsoils under shortduration loading. Soil and Tillage Research, Amsterdam, v.31, n.4, p.235-48, 1994. 
SANTOS, A.B.; PRABHU, A.S. Efeitos de sistemas de colheita e de aplicação de fungicidas no desempenho da soca do arroz irrigado. Revista Brasileira de Engenharia Agrícola e Ambiental, Campina Grande, v.7, n.3, p.572-6, 2003.

SECCO D.; REINERT D.J.; REICHERT, J.M.; ROS, C.O. Produtividade de soja e propriedades físicas de um Latossolo submetido a sistemas de manejo e compactação. Revista Brasileira de Ciência do Solo, Viçosa, v.28, n.5, p.797-804, 2004.

SILVA, V.R.; REINERT, D.J.; REICHERT, J.M. Densidade do solo, atributos químicos e sistema radicular do milho afetados pelo pastejo e manejo do solo. Revista Brasileira de Ciência do Solo, Viçosa, v.24, n.1, p.191-9, 2000.

TORMENA, C.A.; ROLOFF, G. Dinâmica da resistência à penetração de um solo sob plantio direto. Revista Brasileira de Ciência do Solo, Campinas, v.20, n.2, p.333-339, 1996.

WILIKINSON, R.H.; BRAUNBERCK, O.A. Sembradoras en líneas. In: Elementos de maquinária agrícola. Roma: FAO, 1977. v.2, cap.15, p.111-6 (Boletim de Serviços Agrícolas de la FAO, 12). 